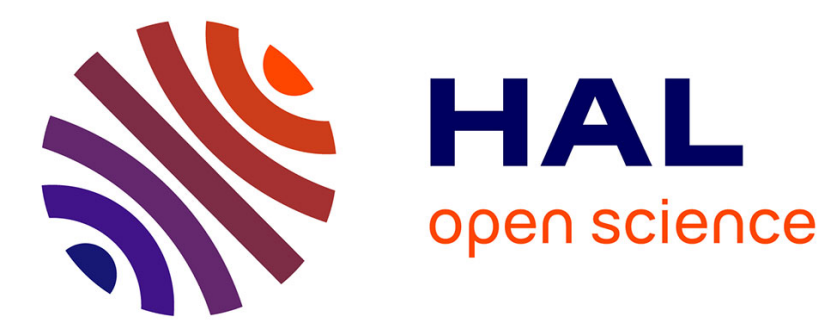

\title{
Is the Lean Organisation a Complex System?
}

Pierre Masai, Pierre Parrend, Nicolas Toussaint, Pierre Collet

\section{To cite this version:}

Pierre Masai, Pierre Parrend, Nicolas Toussaint, Pierre Collet. Is the Lean Organisation a Complex System?. CS-DC'15 World e-conference, Sep 2015, Tempe, United States. hal-01291054

\section{HAL Id: hal-01291054 \\ https://hal.science/hal-01291054}

Submitted on 20 Mar 2016

HAL is a multi-disciplinary open access archive for the deposit and dissemination of scientific research documents, whether they are published or not. The documents may come from teaching and research institutions in France or abroad, or from public or private research centers.
L'archive ouverte pluridisciplinaire HAL, est destinée au dépôt et à la diffusion de documents scientifiques de niveau recherche, publiés ou non, émanant des établissements d'enseignement et de recherche français ou étrangers, des laboratoires publics ou privés. 


\title{
Is the Lean Organisation a Complex System?
}

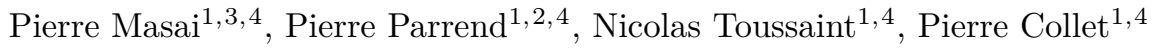 \\ 1 ICube Laboratory, Université de Strasbourg, France \\ pierre.collet@unistra.fr \\ 2 ECAM Strasbourg-Europe, Schiltigheim, France \\ pierre.parrend@ecam-strasbourg.eu \\ 3 Toyota Motor Europe, Bruxelles, Belgium \\ pierre.masai@etu.unistra.fr \\ 4 Complex System Digital Campus (UNESCO Unitwin) \\ http://unitwin-cs.org/
}

Keywords: Complex Systems, Lean, Toyota Production System, Hoshin Kanri, Nemawashi

\begin{abstract}
The Lean Organisation enjoys a tremendous success. It was first developed within Toyota Motor Corporation in the Automotive Industry, but was then adopted by many organisations in all fields of human activities. A deeper observation of this success displays behaviours of complex systems: a high number of agents interact with each other, using basic routines for which they have been coached systematically, creating a much better result than each individual could have reached by themselves (emerging behaviour).

We model two significant processes of Lean: Hoshin Kanri (for management of the organisation objectives) and Nemawashi (consensus building). The simulations performed based on these models show qualitative as well as quantitative evidence for emerging behaviours of the Lean organisation. They also allow to demonstrate the existence of several success factors for the Lean organisation: proficiency of the agents, readiness of the management to accept emergent proposals, and strong requirement for rigour in the execution of the decision process.
\end{abstract}

\section{Introduction}

Lean is a holistic management method. As such, it embeds emergent decision processes, feedback loops through training, coaching for the human actors [Rot10], or kanban for production flow control [SKCU77], and a high connectivity through a highly formalised communication mechanism [CWD06]. This shows intuitively that lots of its core characteristics are tightly bound with complex system behaviours: our hypothesis is that this assumption is true, and that the characterisation of these complex system properties has a high potential impact for identifying the success factors of Lean organisations, and is thus a strong enabler for their efficient implementation. 
In this article, we summarise what Lean is and what the main properties of a Complex System are. We develop our hypothesis on why the Lean organisation exhibits the properties of a complex system, and propose two models showing the behaviour of Lean processes as complex systems: 1) the Hoshin Kanri process (or management of the organisation objectives) which involves different levels of agents (Top Management, Management and employees), spiralling top down and bottom up until a final list of objectives is agreed for the organisation (the 'Hoshin'), 2) the Nemawashi process (or Consensus Building), which spirals bottom up from the person promoting a project until the final approval of this project by the Top Management. Simulations of these models should enable us to better understand the Lean organisation and its success factors.

This paper is organised as follows: section 2 presents the definition and properties of the Lean Organisation. Section 3 characterises the properties of complex systems which are of interest for our model, and presents relevant modelling approaches as well as the stakes of modelling organisations as complex systems. Section 4 introduces the concepts and models of the Hoshin Kanri and the Nemawashi processes. Section 5 specifies the performed simulations and presents their output. Section 6 discusses these outputs and their significance both for modelling Lean organisations as complex systems, and for understanding them better. Section 7 concludes this work.

\section{What is Lean}

In the 25 years since the publication of The Machine That Changed The World [WJR91], based on the Massachusetts Institute of Technology's five-year study on the future of the automobile, the first book in the west revealing what then became known as Lean (the core idea of Lean is to maximise customer value while minimising waste $)^{5}$, the concepts and practices that originated at Toyota have been applied first in the manufacturing of automobiles, where they have been widely adopted, then in the manufacturing of goods in general, and from there it has been applied successfully to all organisation types. When supported from the top as in The Lean Turnaround [BW12] and applied consistently, it has delivered superior results. As examples of application to other sectors and organisation types, let's mention: Lean Start Ups [Rie11], Lean IT [Bel12], Lean Healthcare $^{6}$, Lean Government ${ }^{7}$. The successful application of Lean to so many different environments suggests systemic properties of Lean that we believe are those displayed also by complex systems: many agents interacting with each other to produce results far superior to what each agent could achieve separately.

\footnotetext{
${ }^{5}$ Lean Enterprise Institute Website: http://www.lean.org/whatslean/

6 Marl Graban's blog: http://www.leanblog.org/

${ }^{7}$ Lean Government Starter Kit: http://www.epa.gov/lean/government/
} 


\section{Modelling Complex Systems}

A complex system can be defined as any system consisting of a large number of interacting autonomous entities, creating several layers of collective organisations leading to emerging behaviours [Col14]. In this section, we highlight their core properties, introduce representative modelling approaches, and provide some hints related to the complex system modelling of organisations and enterprises.

\subsection{Properties of complex systems}

Several authors [Hol14,MP07] establish that Complex Adaptive Systems (CAS) are characterised by the following properties:

- Emergence: the whole is more than the sum of the parts. Agents produce together results that far exceed what they could do individually.

- Co-evolution: the agents evolve jointly.

- Connectivity: all entities are connected.

- Distributed Control: the control is distributed to the lowest possible level.

- Far-from-equilibrium: a system without external influences tends to equilibrium, but this is not the case when observing organisations that are constantly evolving based on external conditions, for example creating new rules (a phenomenon called autopoiesis).

- Non-linearity: there is a strong dependency on initial conditions.

- State of paradox: different elements of the system are apparently opposed to each other.

These properties prove to be key to understand the complex behaviour of human-scale systems such as Lean organisations, as discussed in section 6.

\subsection{Complex systems and organisations}

The modelling of organisations as complex systems poses the challenge of modelling discrete entities exhibiting characteristics of complex systems at the meso scale, i.e. at the scale of visible events. Such modelling requires the analysis of three complementary domains: concepts, models, empirical [San13].

Concepts are typically expressed as ontologies [MPZM15]. Models can be either built as Complex Adaptive Systems (CAS) [MP07] or using stochastic approaches [LL05,KF09]. CAS models provide efficient views for representing emerging behaviours from atomic interactions. In cases where emergent properties can be quantified, but the way they emerge is not well understood, stochastic approaches and probabilistic models such as fuzzy logic, probabilistic graphs, or Bayesian behaviours [Hol14,LL05,KF09] enable to identify the relationship between entities. Vensim is a tool supporting this kind of approach [GSS03]. Static relationship structures are best represented as networks [VGB11].

The application of complexity models to the analysis of organisations is often limited to a conceptual level implying emerging structures [MG07], or key 
properties such as 'connectivity and interdependence', 'co-evolution', 'dissipative structures, far-from-equilibrium and history', 'exploration-of-the-space-ofpossibilities', 'feedback', 'self-organisation and emergence', or 'chaos and complexity' [MK03]. Analysis of organisation interactions is a fertile domain for network models, in particular for understanding networks of collaborating enterprises [CM08] or corporate control mechanisms [VGB11].

\section{Modelling Lean}

In the current models, Hoshin Kanri and Nemawashi are considered as isolated processes. The specific Nemawashi process is abstracted in the Hoshin Kanri, and only its output (item selected or not) is considered in the model. The first view for analysing complex systems, i.e. concepts [San13], is given for both of them as ontologies.

\subsection{Definitions}

Hoshin Kanri (Hoshin means Compass, and Kanri means Management in Japanese) is the process by which the objectives are set at various levels in the enterprise, at the function level (like Information Systems), at the Legal Entity Level (like "French Legal Entity") or at the Global Level (companywide). The Hoshin Kanri process is a very typical example of how the Lean organisation is working, because it involves interaction of agents at all levels of the organisation, spiralling up through the layers to enable good ideas from all employees to be adopted at a much higher level, and percolating top down to enable the organisation strategy to reach all employees who will have to play a part in realising it, as shown on Figure 1. It shows the respect for people of the Lean Organisation, enabling all employees to express their ideas, giving strong value to the ideas related to their own area of expertise, that they are recognised to master more than anybody else.

Nemawashi is a Japanese word that conveys the meaning of a tree that is transplanted, taking enough earth around it to enable the tree to survive when planted elsewhere. When taking this analogy to an idea, it means to explain the idea (the tree) to all the stakeholders necessary for its implementation (the earth around the roots) so that it can be brought to implementation with the support (buy in) of all the stakeholders (the transplantation). It is not as such an idea unique to the Lean organisation, but it is used a lot as a technique in Lean because of the importance to value everybody's ideas and input in this organisation form. Figure 2 shows the principle of the Nemawashi process.

If we want to create a model of this Nemawashi process, we have to imagine a representation of the idea, typically an A3 document with visualisations and text. We can model this $\mathrm{A} 3$ by a set of items representing ideas: $\left(i_{1}, i_{2}, \ldots i_{n}\right)$.

The interaction with each stakeholder will result in changes (enrichment by the stakeholder's experience) that will be updated in the document. For example, 


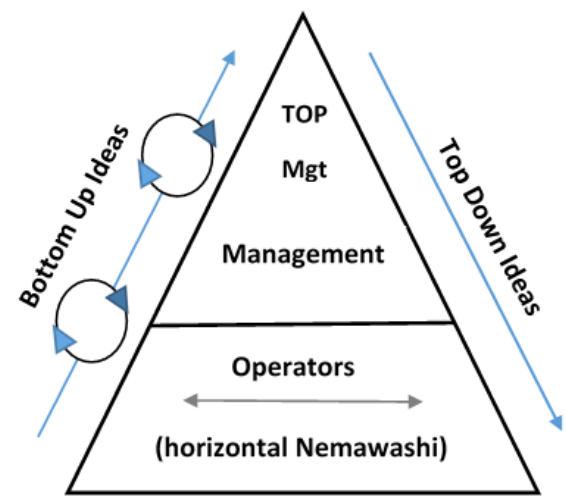

Figure 1: The Hoshin Kanri process

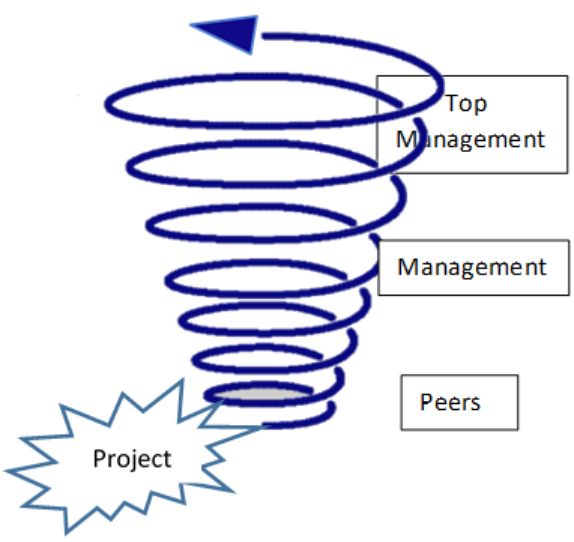

Figure 2: The Nemawashi process

if an item $j_{p}(1 \leq p \leq n)$ is deemed better than $i_{p}$, then it will replace it and the set of items will become: $\left(i_{1}, \ldots, j_{p}, \ldots i_{n}\right)$.

There will be several loops of this interaction, starting with the peers of the agent, then spiralling up the organisation as shown on Figure 2, eventually converging to a better $\mathrm{A} 3$, where each stakeholder will recognise some of their own ideas, which will encourage them to sign the final document and support the project. If a stakeholder did not propose any improvements to the document, none of his points will be on the document, but it is fair to assume that he will approve it.

\subsection{Concepts}

Only the concepts required for the modelling of the processes considered are given here. A more complete ontology of the concepts required for modelling the Lean organisation and their relationship can be found in our previous work [MPZM15].

Hoshin Kanri is characterised by three entities: its participants (top management, middle management, and employees), the items, which are proposals that participants make for potential selection as strategic initiatives for the coming year, and the time, in particular Nemawashi days where the Hoshin Kanri is pushed further through consensus between the employees of the organisation at the different levels. Figure 3 shows the ontology for the Hoshin Kanri process.

Nemawashi is characterised by three entities: its participants, identical to those of Hoshin Kanri, the items, which are also found at the Hoshin Kanri level, but also the specific project bound with these items and proposals, i.e. items being considered for adoption. Figure 4 shows the ontology for the Nemawashi process. 


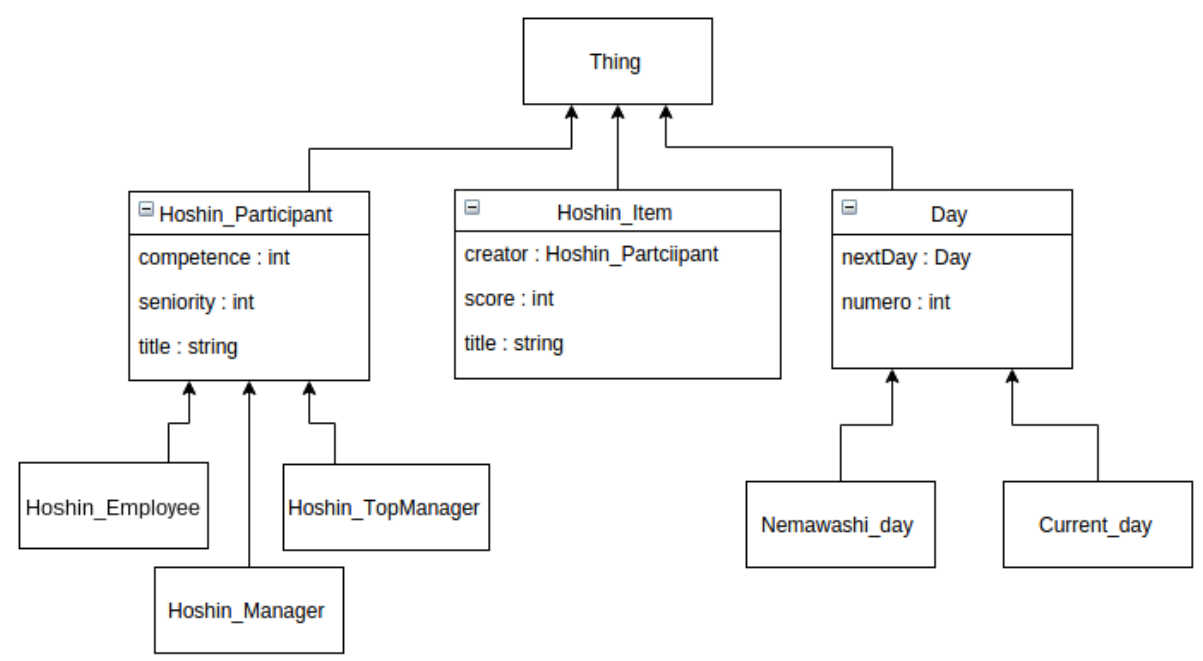

Figure 3: Hoshin Kanri Ontology

\section{Simulations}

The models of both processes described in the previous section are implemented to demonstrate their behaviour in time, and to challenge the hypothesis of the Lean organisation being a complex system.

The Hoshin Kanri is modelled as agents interacting in a stochastic manner. These agents are implemented first in an object oriented way in the Python ${ }^{8}$ language, then abstracted as a set of probabilistic rules with Drools ${ }^{9}$ embedding an identical behaviour.

The Nemawashi is implemented as a set of probabilistic rules only.

\subsection{Hoshin Kanri}

A Hoshin Kanri process is performed each year so as to determine the strategic initiatives to be taken and then enforced in the next business year. An initial set of proposals is generated, made public to the organisation, and all employees can propose their own improvements. Better proposals are kept, weaker ones are removed. The objective of the simulation is to evaluate the impact on the resulting decisions, based on the interactions between the organisation agents of:

1. the quality of initial proposals,

2. the emitter of initial proposals, either Top Management or all employees,

3. the seniority and skills of employees and managers,

4. the elapsed time.

\footnotetext{
${ }^{8}$ https://www.python.org/

${ }^{9}$ http://www.drools.org/
} 


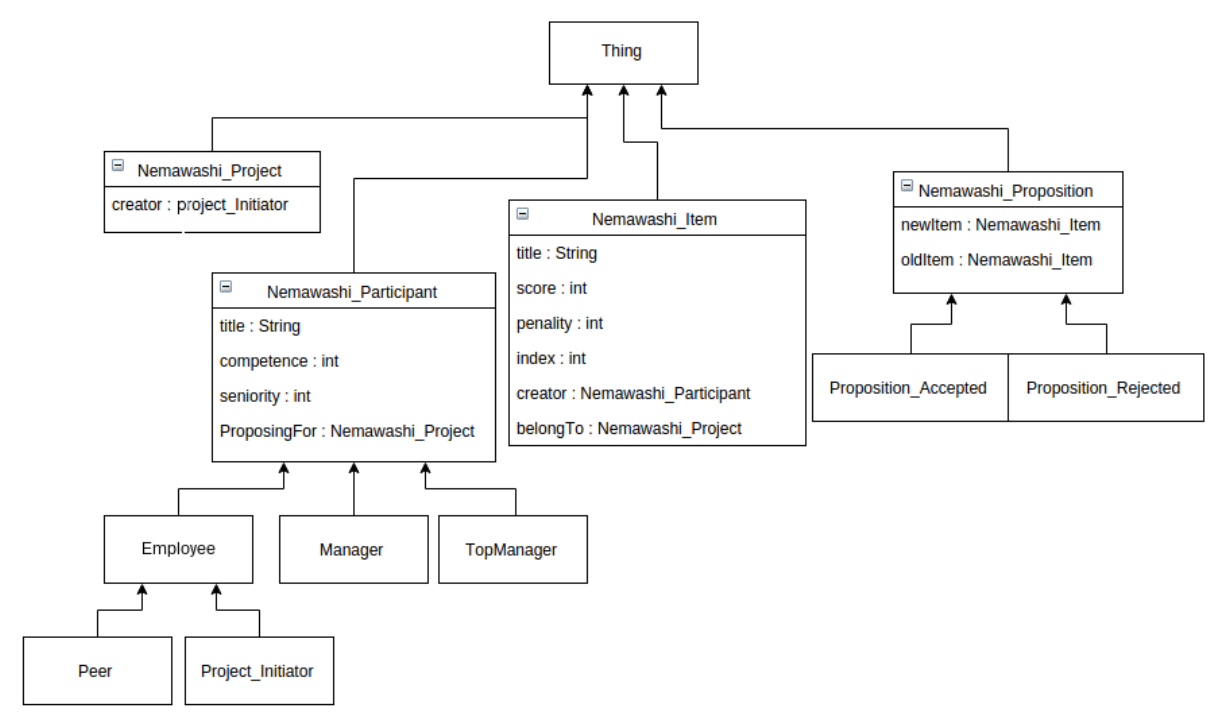

Figure 4: Nemawashi Ontology

Simulation parameters are driven from our experience:

- the Hoshin Kanri process is simulated on a period of 90 days, or three months, which is the typical time frame used for this.

- the agents are at three levels: Top Management, Management and employees.

- two types of initialisations can be performed: either the Top Management proposes the initial items, or everybody in the organisation can do.

- the Hoshin items produced are scored based on a simple rating based on seniority and experience of each agent. This makes it more likely that Top Management or Management will have their proposed items retained; however it does not make it a fatality.

- the frequency of items input accelerates towards the end of the process, which has been simulated here by a reverse Fibonacci sequence:

$$
y_{i}=90-f_{i}, \text { for } i=1,10 \text {, giving }:(89,88,87,85,82,77,69,56,35,1)
$$

- the model presented here is abstracted, because items are often not replaced by others as a whole, but interaction between the agents at various levels also use the Nemawashi model to merge several items in a more valuable one.

The quality of proposals is represented on an arbitrary scale from 0 to 100 , with 100 representing a higher quality and 0 a lower quality. This quantification enables to abstract the comparison process between two items: the better item is kept, the weaker is removed.

Figure 5 shows the evolution in time of the average item value for the Hoshin Kanri process, for varying initialisation processes (by Top Management/by everybody) and varying skill level of employees of the organisation (Weak Peers/ 
Strong Peers). When the Top Management issues the initial items, the resulting decision quality, as one can expect, depends on the feedback of the employees: if the employees have weaker skills, the resulting decisions will have a lower overall quality. When the employees have a high seniority and proficiency, an interesting phenomenon occurs: employee-driven Hoshin Kanri leads to results as good as Top Management-driven Hoshin Kanri. In this case, the presence of management seems to be useless. Actually, these results matches interestingly enough a radical shift in the culture of Lean organisations: the role of leaders is to enable emergence, not to take (all) the decision themselves.

Figure 6 shows the evolution of the number of items remaining from the original proposal in the Hoshin Kanri process. This number converges for the different configurations, except when the Top Management initialises the process and the employees have a weaker seniority and skill level. In this case, as can be expected, fewer modifications are observed.

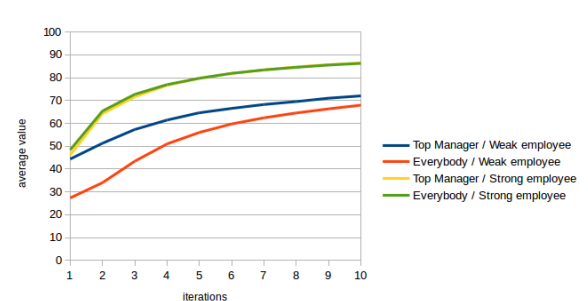

Figure 5: Evolution in time of the average item value for Hoshin Kanri

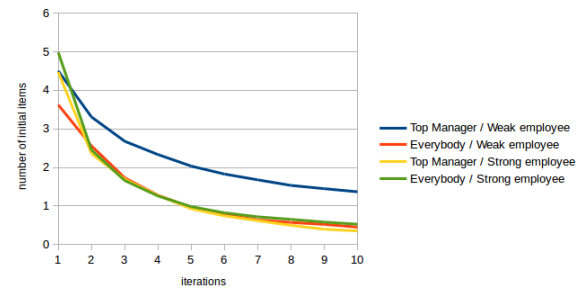

Figure 6: Evolution of the number of items kept from the original Hoshin Kanri proposal

It is worth noting that employee-driven Hoshin Kanri with weaker employee seniority and skills lead to as many new proposals and thus rework than when the employees are more experienced. If we compare these results to those from Figure 5, we see that the same amount of energy will then be spent to achieve weaker results. When the employees have weaker experience, the Hoshin Kanri process should better be led by the Top Management.

\subsection{Nemawashi}

The Nemawashi process is performed at each step of the Hoshin Kanri for building consensus. We focus here on the consensus building process itself, independently of its potential integration in the Hoshin Kanri.

The core simulation parameters are the seniority value (in years), as well as the competence value (a score of 1 to 10) of the Nemawashi_Participant.

The first step is the creation of a project by the initiator. He puts 20 items in it (for example 20 items on an A3 document). Each item is generated with an id, a penalty value (initialised to 0 ), and a score. 
The maximum score for the Nemawashi items is given by following equation:

$$
\text { max_score }=\text { initiator's seniority * initiator's competence }
$$

Then, the item score is randomly chosen between 0 and the maximum score. The penalty is incremented each time that a participant gives a proposition to replace it with a better item and when the initiator does not consider it. The higher the penalty, the higher the chance it will be replaced.

Once the project is initiated, the initiator will show it to his peers, then to the managers, and finally to the Top Manager to enhance it with the experience of all the participants. Each of them will see some items and if they have a more valuable idea, propose it to the initiator. The probability that the initiator accepts to swap the item is given by following equation:

$$
p=(\text { score of the new item }+(5 * \text { penalty of the project's item })) / 100
$$

If the initiator rejects the new idea, the penalty of the project's item is incremented. Otherwise the items are exchanged. Moreover, if the initiator rejects all the items of a manager, there is $80 \%$ chance that the manager won't sign (proposing new items again), and 10\% in the case he accepts at least one of the manager's ideas. If the manager is satisfied and doesn't challenge other items, he gives his agreement to the project and signs it. At the end, the top manager can reject the whole project with a probability of $5 \%$.

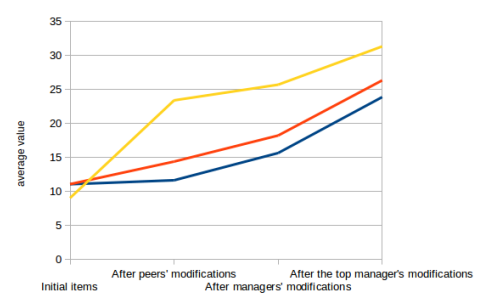

Figure 7: Evolution in time of the average item value for Nemawashi

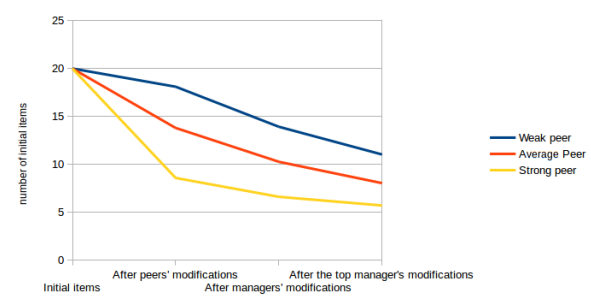

Figure 8: Evolution of the number of items kept from the original Nemawashi proposal

Figure 7 shows the evolution in time of the average item value for the Nemawashi process, according to the skill level of employees. Highly skilled employees achieve a good result even without management intervention. Employees with standard or below average skill levels achieve a less efficient Nemawashi, even with management intervention. Figure 8 shows the evolution of the number of items kept from the original proposal for the Nemawashi process. Initial items are rapidly withdrawn by skilled employees, whereas several iterations of management are required to improve the proposal set with less skilled employees. 


\section{Discussion}

\subsection{Modelling Lean Organisations as complex systems}

Let's now consider again the properties of complex systems and see how the Lean organisation exhibits those properties, based on our simulations:

- Emergence: In the Nemawashi process, an individual can enrich his process gradually by spiralling up the layers of management and getting good advice integrated in his project. In Hoshin Kanri, even ideas sent top down by the Top Management are challenged and enriched by the whole organisation, creating a better set of objectives, with a better buy in from the whole organisation. The Lean organisation thus creates more emerging patterns than more traditional forms of organisation.

- Co-evolution: the modelled processes mandate systematic involvement of all levels of the organisation, with an impact that evolves based on their seniority and experience. This encourages the co-evolution of the agents.

- Connectivity: all entities are connected from the processes spiralling up and down and extending horizontally between peers.

- Distributed Control: the initiative is given to the agents (employees) to come up with ideas/projects, and defend them through the organisation. While comments are given at all levels to enrich the projects, the control is left with the initiator of the project, who is respected by the various layers of management.

- Far-from-equilibrium: the Lean organisation is never at equilibrium. The evolution of the world outside the organisation leads to Hoshin items proposed by Top Management and discussed within the organisation. Each project proposed can lead to major changes, which will be applied more effectively as different levels of management are involved in the Nemawashi process.

- Non-linearity: a big dependence on slightly different initial conditions is observed. When slightly different instructions are given at the beginning of the Hoshin process, the following top-down and bottom-up interactions may lead to a very different final Hoshin document, hence the importance to start the process with parameters that are carefully considered after deep reflection of the previous cycle (Called Hansei - Reflection in Japanese).

- State of paradox: This issue expands beyond the current models. It is best illustrated by the paradox of Just in Time, mandating a continuous flow of logistics and production pulled by the customer and Jidoka ('automation with a human touch') which mandates to stop the same flow as soon as a defect occurs.

Building on this basis, and on our work developing an ontology of Lean with Rules to operate on it, we shall further work on modelling several processes typical of the Lean Organisation, and gradually enrich the models with the experience derived from the practice of Lean in different contexts. 


\subsection{What we learnt about Lean Organisations}

Lean organisations aim at structuring an emergent system enabling the employees, or operators, to deeply impact the organisation strategy according to actual issues in the organisation. Figure 5 shows that, in optimal conditions, this is actually the case.

The model and simulation results isolate three critical success factors for emergent strategy definition through Hoshin Kanri and Nemawashi:

- the proficiency of employees, which enables them to make proposals as good as the management thanks to a finer knowledge of the organisation, and reduces the communication overhead by getting quicker results; when the employees have weaker experience, the Hoshin Kanri process should better be led by the Top Management.

- the readiness of Management to accept emerging strategic proposals, to take advantage of this proficiency,

- the rigour in the execution of the emergent decision process, which can be realistic (the time pressure and increase of activity as a deadline is approaching is a natural tendency in all human structures) but needs to be successfully completed to fulfil the decision refinement process.

The model focuses on the quantified quality of the proposals. It does not take the alignment between employees and management into account, which is considered as a key success factor in many organisations [JKP03,BVLT05] and is thus an additional critical success factor.

\section{Conclusions and perspectives}

A complexity-based model of a Lean organisation needs to entail three complementary views [San13]: the conceptual view, the model view, and the empirical view. Based on the concepts defined in previous works [MPZM15], we introduce here a first model of two representative processes of the Lean enterprise: the Hoshin Kanri process, for collaborative choice of the management objectives, and the Nemawashi process, for consensus building. Qualitative behaviour of complex systems are observed in the Lean organisation: emergence, co-evolution, connectivity, distributed control, non-linearity, as well as state of paradox. Then Hoshin Kanri and Nemawashi are modelled using agents on one hand and probabilistic rules on the other hand to validate the field observations. Significant results are highlighted, in particular the emergent behaviour of the Hoshin Kanri process.

The proposed model enables to demonstrate a ground-breaking property of Lean organisations: through Nemawashi and Hoshin Kanri, emergent strategies can be defined effectively by proficient employees, with little to no added value brought by the management. Though companies like Toyota do not claim they can work without management, they confirm that managing a Lean organisation requires shifting from a traditional authoritative to a leader-servant governance 
style. A few smaller companies, however, like Favi ${ }^{10}$ or Poult ${ }^{11}$ for instance in France, have already successfully implemented a 'freed' management style where radical emergence is leading to financial success for the company, confirming, in spite of the numerous practical obstacles, the credibility of the proposed model.

\section{Scientific Validation}

This paper has been unanimously validated in a collaborative review mode with the following reviewers:

- Paula Castaneda, National University of San Martin, Buenos Aires, Argentina.

- Ricardo Palma, University of Mendoza, Argentina.

- Imane Bouhaddou, Ecole Nationale Supérieure des Arts et Métiers (Meknès, Maroc).

- Ismaïla Diouf, Université Cheikh Anta Diop (Dakar, Sénégal).

\section{References}

[Bel12] S.C. Bell. Run Grow Transform: Integrating Business and Lean IT. CRC Press, 2012.

[BVLT05] Michael Beer, Sven C Voelpel, Marius Leibold, and Eden B Tekie. Strategic management as organizational learning: Developing fit and alignment through a disciplined process. Long Range Planning, 38(5):445-465, 2005.

[BW12] A. Byrne and J.P. Womack. The Lean Turnaround: How Business Leaders Use Lean Principles to Create Value and Transform Their Company. BusinessPro collection. McGraw-Hill Education, 2012.

[CM08] Balázs Csanád Csáji and László Monostori. A complexity model for networks of collaborating enterprises. In Proceedings of the 17th World Congress of IFAC (International Federation of Automatic Control), COEX, Seoul, 2008.

[Col14] Pierre Collet. Mooc ose (optimisation stochastique evolutionnaire), September 2014 .

[CWD06] Catherine Cassell, JM Worley, and TL Doolen. The role of communication and management support in a lean manufacturing implementation. Management Decision, 44(2):228-245, 2006.

[GSS03] Andreas Größler, Myrjam Stotz, and Nadine Schieritz. A software interface between system dynamics and agent-based simulations: linking vensim $\mathbb{R}$ and repast $\AA$. In Proceedings of the 21 st system dynamics society international conference. Citeseer, 2003.

[Hol14] J.H. Holland. Complexity: A Very Short Introduction. Very Short Introductions. OUP Oxford, 2014.

$\overline{10}$ http://ayeba.fr/2014/01/linnovation-par-les-méthodes-de-management-le-cas-favi/

${ }^{11}$ https://imatechnologies.wordpress.com/2013/06/15/poult-raconte-son-histoire-deliberation/ 
[JKP03] Maheshkumar P Joshi, Ravi Kathuria, and Stephen J Porth. Alignment of strategic priorities and performance: an integration of operations and strategic management perspectives. Journal of Operations Management, 21(3):353-369, 2003.

[KF09] Daphne Koller and Nir Friedman. Probabilistic graphical models: principles and techniques. MIT press, 2009.

[LL05] Zhi Liu and Han-Xiong Li. A probabilistic fuzzy logic system for modeling and control. Fuzzy Systems, IEEE Transactions on, 13(6):848-859, 2005.

[MG07] Zahir Messaoudene and José Gramdi. Proposition d'un cadre conceptuel et systémique des systèmes de production lean. Yè Congrès international de Génie Industriel, Trois Rivières, Québec, 2007.

[MK03] Eve Mitleton-Kelly. Complex systems and evolutionary perspectives on organisations: the application of complexity theory to organisations. Elsevier Science Ltd, 2003.

[MP07] John H. Miller and Scott E. Page. Complex Adaptive Systems: An Introduction to Computational Models of Social Life (Princeton Studies in Complexity). Princeton University Press, Princeton, NJ, USA, 2007.

[MPZM15] P. Masai, P. Parrend, and C. Zanni-Merk. Towards a formal model of the lean enterprise. In 19th International Conference on Knowledge Based and Intelligent Information and Engineering Systems, Sep, to be published 2015.

[Rie11] E. Ries. The Lean Startup: How Today's Entrepreneurs Use Continuous Innovation to Create Radically Successful Businesses. The Lean Startup: How Today's Entrepreneurs Use Continuous Innovation to Create Radically Successful Businesses. Crown Business, 2011.

[Rot10] Mike Rother. Toyota kata. MacGraw Hill, 2010.

[San13] Lena Sanders. Problématiques géographiques, systèmes complexes et modélisation. In Rencontres nationales Systèmes Complexes (RNSC), 2013.

[SKCU77] Y Sugimori, K Kusunoki, F Cho, and S Uchikawa. Toyota production system and kanban system materialization of just-in-time and respectfor-human system. The International Journal of Production Research, 15(6):553-564, 1977.

[VGB11] Stefania Vitali, James B Glattfelder, and Stefano Battiston. The network of global corporate control. 2011.

[WJR91] James P. Womack, Daniel T. Jones, and Daniel Roos. The Machine That Changed the World: The Story of Lean Production. The MIT international motor vehicle program. HarperCollins, 1991. 